\title{
Estimating an Aggregate Economic Genotype to Facilitate Breeding and Selection of Strawberry Genotypes in Southeast Queensland
}

\author{
Mark E. Herrington ${ }^{1}$ \\ Horticulture and Forestry Science, Agri-Science Queensland, Department of Agriculture, Fisheries \\ and Forestry, Maroochy Research Facility, Nambour, Queensland 4560, Australia; and The \\ University of Queensland, School of Agriculture and Food Sciences, Brisbane, Queensland 4072, \\ Australia
}

\author{
Craig Hardner and Malcolm Wegener \\ The University of Queensland, School of Agriculture and Food Sciences, Brisbane, Queensland \\ 4072, Australia
}

\author{
Louella Woolcock \\ Horticulture and Forestry Science, Agri-Science Queensland, Department of Agriculture, Fisheries \\ and Forestry, Maroochy Research Facility, Nambour, Queensland 4560, Australia
}

\begin{abstract}
Mark J. Dieters
The University of Queensland, School of Agriculture and Food Sciences, Brisbane, Queensland 4072, Australia
\end{abstract}

\begin{abstract}
AdDITIONAL INDEX wORDs. breeding objective, economic weight, estimated breeding value, Fragaria $\times$ ananassa, gross margin, profitability index

Abstract. The Queensland strawberry (Fragaria $\times$ ananassa) breeding program in subtropical Australia aims to improve sustainable profitability for the producer. Selection must account for the relative economic importance of each trait and the genetic architecture underlying these traits in the breeding population. Our study used estimates of the influence of a trait on production costs and profitability to develop a profitability index (PI) and an economic weight (i.e., change in PI for a unit change in level of trait) for each trait. The economic weights were then combined with the breeding values for 12 plant and fruit traits on over 3000 genotypes that were represented in either the current breeding population or as progenitors in the pedigree of these individuals. The resulting linear combination (i.e., sum of economic weight $\times$ breeding value for all 12 traits) estimated the overall economic worth of each genotype as $\mathrm{H}$, the aggregate economic genotype. $\mathrm{H}$ values were validated by comparisons among commercial cultivars and were also compared with the estimated gross margins. When the $H$ value of 'Festival' was set as zero, the $H$ values of genotypes in the pedigree ranged from -0.36 to +0.28 . H was highly correlated $\left(R^{2}=0.77\right)$ with the year of selection (1945-98). The gross margins were highly linearly related $\left(R^{2}>0.98\right)$ to $H$ values when the genotype was planted on less than $50 \%$ of available area, but the relationship was non-linear [quadratic with a maximum $\left(R^{2}>0.96\right)$ ] when the planted area exceeded $50 \%$. Additionally, with $H$ values above zero, the variation in gross margin increased with increasing $\mathrm{H}$ values as the percentage of area planted to a genotype increased. High correlations among some traits allowed the omission of any one of three of the 12 traits with little or no effect on ranking (Spearman's rank correlation 0.98 or greater). Thus, these traits may be dropped from the aggregate economic genotype, leading to either cost reductions in the breeding program or increased selection intensities for the same resources. H was efficient in identifying economically superior genotypes for breeding and deployment, but because of the non-linear relationship with gross margin, calculation of a gross margin for genotypes with high $H$ is also necessary when cultivars are deployed across more than $50 \%$ of the available area.
\end{abstract}

The Queensland strawberry breeding program aims to sustainably increase profitability for the producer by selecting superior genotypes. To be effective and efficient, selection must account for several traits simultaneously and focus on: 1) the most economically important traits; and 2) the ease with which the levels of traits can be changed by selection. Thus, the

Received for publication 27 Dec. 2013. Accepted for publication 3 Feb. 2014. This project was jointly funded by The Queensland Government through its Department of Agriculture, Fisheries and Forestry (DAFF) and Horticulture Australia Limited (HAL) using the Strawberry Industry Levy and matched funds from the Australian Government.

${ }^{1}$ Corresponding author. E-mail: mark.herrington@daff.qld.gov.au. breeder must account for and connect the relative economic importance of traits and the genetic architecture of the traits underlying the population to achieve maximum genetic progress toward a nominated economic goal.

The breeding objective or aggregate economic genotype or overall economic index describes the aggregate breeding value to be improved and is a tool for determining the importance of a trait within a multitrait breeding program and is usually expressed in economic terms (Solkner et al., 2008). Here the genetic information of estimated breeding values (EBVs) is connected to economic information relating to farm profit that reflects the distribution of financial rewards throughout the 
whole industry (Barwick et al., 1991, 2003; Barwick and Henzell, 2005). Hazel (1943) formalized the concept of aggregate economic genotype $(\mathrm{H})$, which is most commonly called the breeding objective in livestock and plantation trees, as a linear combination of additive genetic values of two or more traits weighted by their relative economic values:

$$
H=v_{1} a_{1}+v_{2} a_{2}+\ldots+v_{j} a_{j}+\ldots+v_{n} a_{n}=\mathbf{v}^{\prime} \mathbf{a}^{\prime},
$$

where $\mathbf{v}^{\prime}=\left[v_{1}, v_{2}, \ldots v_{j}, \ldots v_{n}\right]$ is the vector of relative economic values of traits 1 to $\mathrm{n}$ and $\mathbf{a}^{\prime}=\left[a_{1}, a_{2} \ldots a_{j} \ldots a_{n}\right]$ is the vector of additive genetic values. Thus, the aggregate economic genotype is a particular combination of weighting factors (economic weights or values) and genetic information (EBVs) of all the traits to be improved (Falconer and Mackay, 1996). The economic weight represents the benefit of one unit improvement of the trait without altering other traits in the population (Hazel, 1943).

The relative economic values can take a number of approaches; e.g., profit, return on investment, cost per unit of production, etc. Apiolaza and Garrick (2001) used incremental change in profit with change in the level of each trait to develop weights. However, this profit formulation is claimed to include scaling components such that improvements could be made by changing the size of the farming operation rather than the need to change the genetic base (Ponzoni, 1988). Ratio forms of economic value are claimed to avoid this scaling effect (Ponzoni, 1988). However, Smith et al. (1986) claimed there would be only small differences among the forms. Additionally, the profit and ratio forms were shown to be equivalent when profit [i.e., when net earnings in an accountant's sense minus the farm's (firm's) opportunity cost of capital] was set at zero in an economic sense (Brascamp et al., 1985; Ponzoni, 1988). Profit is zero in an economic sense when the farm (firm) earns the normal economy-wide rate of profit in an accounting sense. By contrast, Melton and Colette (1993) argue that the most important criteria is that the weighting values reflect the contributions to economic improvement of the enterprise and so advocate a more detailed approach than input output ratios for complex evaluations (e.g., commercial beef herd). Doupe and Lymbery (2003) support this view and also indicate that using a ratio alone as a selection criterion does not allow an accurate prediction of response to selection. Hardner et al. (2006) combined both profit and ratio forms to efficiently use ratios based on profit through a PI to develop relative economic weights for traits in a horticultural production system for macadamia (Macadamia integrifolia and M. tetraphylla). This combination of profit and ratio is also likely to be appropriate for use in strawberry.

The advantages claimed from using a breeding objective in livestock and plantation trees, and calculating the economic weights for various traits, should also apply to strawberry improvement. The use of an aggregate economic genotype (breeding objective) should enable breeders to direct their activities to combine traits with the highest estimated breeding values and make the most rapid (total) genetic progress for their particular situation.

Development of an aggregate economic genotype (breeding objective) can be described in the following phases: specification of the breeding, production, and marketing system; identification of sources of income and expense; determination of biological traits influencing income and expense; estimation of phenotypic and genetic parameters (i.e., breeding values) and choice of selection criteria; and derivation of the economic weights (values) of each trait (Ponzoni and Newman, 1989). The ideal aggregate economic genotype (breeding objective) should be composed of all traits that influence returns and costs, regardless of whether they can be changed by selection or measured (Ponzoni and Newman, 1989).

The formal definition of a breeding objective and identification of selection criteria based on this objective should be the first step in developing a structured breeding program (Apiolaza and Garrick, 2001). Despite this, although general combining abilities or breeding values associated with traits have been reported for horticultural crops (Souza et al., 2000; Tancred et al., 1995), there is only one published example of the formal definition of a breeding objective (aggregate economic genotype) in horticultural crops (Hardner et al., 2006). Additionally, although selection indices based on economic criteria have been developed (Wenzel, 1980), there is no report of an aggregate economic genotype (breeding objective) involving multiple traits in strawberry.

Herrington et al. (2012) described the contribution of 12 individual plant and fruit traits to farm cost and income under subtropical Queensland conditions with the overall goal of improving the profitability of the industry through the release of new strawberry cultivars. The study involved specifying the production and marketing system in southeast Queensland, developing a spreadsheet to assess the economic impact of changes to the system, and identifying plant traits that influenced outcomes from the system. The traits included total yield, early yield, fruit size, fruit size variation, and plant size, display of fruit, truss branching, ease of detaching fruit, resistance of fruit to rain damage, abrasion, and bruising. These traits and the levels of expression of the traits were related to the amount of marketable fruit available for sale and the cost (based on time) to gather and consolidate fruit into a marketable unit. Additionally, the analysis related total volume of farm production to market prices received. Genetic parameters associated with the traits have also been estimated (M.E. Herrington, unpublished data). Because of the importance of defining the breeding objective (Apiolaza and Garrick, 2001), but its lack of formal use in strawberry, our study used this information to produce a linear combination of economic and genetic parameters to estimate the aggregate economic genotype (i.e., breeding objective) for over 3000 genotypes that are represented in the breeding program or the pedigree of individuals in the breeding program relevant to strawberry production in southeast Queensland. Associations with gross margin and the effect of reducing the number of traits in the model were also investigated.

\section{Materials and Methods}

IDENTIFICATION OF SOURCES OF INCOME AND EXPENSE. All sources of income and expense in commercial strawberry production in southeast Queensland were previously identified and a production function and profit equation developed (Herrington et al., 2012). The gross margin (Australian dollars per hectare) of this function was based on a whole of industry production approach (i.e., assuming farms are using similar production systems). The function accommodates up to three cultivars contributing to production on the one farm, because using more than one cultivar is a normal practice in southeast Queensland, where 'Festival' is the major current commercial 
cultivar and in 2011 comprised $\approx 50 \%$ of plantings. Additionally, the production function and profit equation adjust the expected prices according to: 1) the timing of production over the season May through September; and 2) to the volume of fruit on the market. It can also accommodate changes in levels of up to 12 traits and responds to some additional production parameters (e.g., rainfall). The gross margin calculation included variable production and marketing costs but did not include fixed costs such as administrative expenses and capital charges for land rental, depreciation, etc.

Derivation OF THE BREEDING VALUES OF GENOTYPES FOR EACH TRAIT. Additive genetic values $(a)$ for 12 traits for each genotype were obtained using best linear unbiased prediction [BLUP (Henderson, 1975)] to estimate breeding values. To estimate these breeding values, we followed the concepts of Durel et al. (1998) who, in the absence of a well-structured formal crossing design, used pedigree information to estimate genetic parameters from large unbalanced data sets in apple (Malus $\times$ sylvestris var. domestica) comprising 213 families, Silva et al., (2004), who estimated additive and non-additive genetic parameters from clonally replicated and seedling progenies of Eucalyptus globulus from a partial diallel mating design, and Oakey et al. (2006), who used a combination of wheat lines with known and unknown pedigrees to simultaneously select the best performing lines for commercial release and identify the best parents for future breeding. The use of the BLUP (Henderson, 1975) allows adjustment for differing amounts of information inherent within unbalanced designs, making use of all information, on all individuals for which records of phenotypic values and pedigrees are available (Bauer and Leon, 2008; Souza et al., 2000), and they can be applied to selected populations (Henderson, 1975). We applied mixed model methods to the unbalanced clonal trial data accumulated in the Queensland strawberry breeding program on 1607 genotypes over a 6-year period (from 2004 to 2009) to estimate genetic parameters and predict breeding values (Dieters et al., 1995, 1996; Hardner et al., 2012; Lynch and Walsh, 1998; Mrode 2005) using ASReml software (Gilmour et al., 2006). The 3008 genotypes estimated in the analysis were from the pedigree data file associated with the 1607 genotypes evaluated in field trials. These latter represented $2 \%$ of the original seedling populations derived from up to 60 families per year produced each year by intercrossing a total of 133 genotypes as male and 100 as female parents (including 48 as both). The analyses included the incorporation of full pedigree information, adjustment for trial spatial effects, amalgamation of sampling dates within years and combination of data across years (breeding cycles). The traits chosen included those expected to most strongly influence economic outcomes with an emphasis on cost of production (Herrington et al., 2012). As a result of unavailability of economic data, consumer-oriented traits (e.g., sweetness, internal color, external color, glossiness, and acidity) were not included in these analyses. For the chosen traits, the total genetic variance $\left(\mathrm{V}_{\mathrm{GT}}\right)$ in the breeding population was more than $50 \%$ of the phenotypic variance $\left(\mathrm{V}_{\mathrm{P}}\right)$ and additive genetic variance $\left(\mathrm{V}_{\mathrm{GA}}\right)$ was more than $80 \%$ of $\mathrm{V}_{\mathrm{GT}}$ (M.E. Herrington, unpublished data).

Pack-out percentage was fixed at a base level of $85 \%$ (Queensland Strawberry Industry Promotions Council, 2006) and was not included as a separate variable trait because the crop was taken to be well managed and workers were assumed to be sufficiently careful so that damage both attributable to pest and disease infestation and to physical damage of human origin was negligible. Variation in pack-out was considered to be caused by two other traits, namely: fruit appearance (shape) (determined by a visual assessment of regularity and uniformity of fruit shape) and resistance to rain damage [where for a given rain event, marketable fruit yield was reduced, such that marketable yield $=$ total yield $\times$ resistance to rain damage (percentage)].

DERIVATION OF THE ECONOMIC WEIGHTS (v) OF EACH TRAIT. The industry economic data were produced after modifying the parameters of the gross margin analysis used by Herrington et al. (2012). Specifically, in parameterizing the gross margin (GM) in the present study, early yield included production in both May and June (with equal yields assumed in both months) and total yield comprised early yield plus production in both July and August (with equal yields assumed in July and August).

Marginal changes in yield were applied at $1.0 \mathrm{~g} / \mathrm{plant}$. With early yield this was distributed as $0.5 \mathrm{~g} /$ plant for both May and June, whereas at the same time, $0.5 \mathrm{~g} /$ plant was simultaneously deducted from each of both July and August so as to maintain a constant total yield. With total yield, the increase was distributed as $0.25 \mathrm{~g} /$ plant for each month from May through August. This, therefore, added $0.5 \mathrm{~g} / \mathrm{plant}$ to early yield and $0.5 \mathrm{~g} / \mathrm{plant}$ to residual (late) yield. The analyses used trait values (i.e., the BLUP EBV) of 'Festival' as the base value for all traits, an industry plant population of 35 million plants, and a linear response in cost to the level of a trait over the range of levels encountered.

To provide base values from which to derive economic weights $(v)$, the economic values for the strawberry enterprise were taken from the modified gross margin (as described in the preceding) and converted into a PI following Hardner et al. (2006). The PI was calculated as the ratio of GM to input costs (IC); i.e., PI = GM/IC. PI was then recalculated for unit changes in the level of the expression of each trait. The economic weight was calculated as the change in PI $(\triangle \mathrm{PI})$ for a unit change $(\triangle$ unit) in the trait (i.e., $v=\triangle \mathrm{PI} / \triangle$ unit).

ESTIMATION OF THE AGGREGATE ECONOMIC GENOTYPE FOR EACH GENOTYPE. The aggregate economic genotype for each genotype was estimated by a linear combination across traits of $a$ (i.e., EBV) weighted by the relative economic weight $(v)$. This was applied to all genotypes in the pedigree list (i.e., a total of 3008 individuals that were represented in the data or in the pedigree of the individuals evaluated).

RELATIONSHIP BETWEEN AGGREGATE ECONOMIC GENOTYPE AND GROSS MARGIN. To validate whether the aggregate economic value of genotypes reflects the economic value of a genotype when deployed commercially as a cultivar, we examined the correlation between $\mathrm{H}$ and the year of selection for 13 important cultivars selected from 1945 to 1998 . It was hypothesized that because after trialing new cultivars, growers will adopt them only if it makes economic sense, the gross margin of the dominant cultivar would increase with time, (i.e., as a more profitable cultivar replaced a less profitable one). Second, 32 genotypes that had been evaluated in field trials during the 2004-09 period were randomly selected from seven approximately equally spaced segments (three to nine samples per segment) of the distribution of $H$ values. The GMs were estimated for each of these 32 genotypes, assuming in each case that each genotype was used exclusively by the whole industry.

Next, the assumption used to simplify estimating economic weights, i.e., that all industry used only one cultivar, was 
relaxed to estimate further gross margins. A farm will not normally make a total change to a new cultivar (i.e., genotype) without adequate testing and phase-in. Therefore, a farm was assumed to comprise three cultivars, two important commercial cultivars, Festival and Rubygem, in equal proportions, and the third the candidate genotype. GM was estimated when the portion of the farm allocated to the test genotype was $0 \%, 5 \%$, $25 \%, 50 \%, 75 \%$, and $100 \%$. Within each percentage allocation, the estimated GM for a candidate genotype was regressed using linear, polynomial, and nonlinear forms on the corresponding $H$ value. The simplest model and the highest percentage of variance accounted was selected as the final model. In all cases, Genstat (14th Edition; Lawes Agricultural Trust, Rothamsted, U.K.) was used for these correlation and regression analyses.

EFFECT OF ELIMINATING INDIVIDUAL TRAITS ON THE AGGREGATE ECONOMIC GENOTYPE VALUE. Evaluation of traits can be expensive. Evaluation of fewer traits may reduce costs and increase effectiveness or allow increased selection intensity (i.e., larger populations) for the same resources. The ranking of genotypes based on an initial $\mathrm{H}$ with 12 traits and that when one trait was omitted were examined. Little change in rank would provide evidence that the trait could be omitted; i.e., a reduced $\mathrm{H}$ could be as effective. The candidate traits for omission were identified as those with high correlations with other traits and or those making an insignificant contribution to $\mathrm{H}$. Traits with high correlations $(r>0.7)$ and traits with a small spread in $v a$ were identified; total yield with early yield $(r=0.75)$; resistance to abrasion with resistance to bruising $(r=0.82)$; and variation in fruit size (VFSZ having a small spread in $v a$ ). The first trait in each pair, or the single trait, was omitted separately and the new $\mathrm{H}$ values were estimated. Rank correlations between $\mathrm{H}$ with and without each trait across all 3008 genotypes were estimated using Spearman's rank correlation (Genstat 14th Edition).

\section{Results}

ECONOMIC WEIGHTS OF TRAITS, ESTIMATED BREEDING VALUE OF GENOTYPES FOR TRAIT, AND A COMBINATION INTO AN AGGREGATE ECONOMIC GENOTYPE. Economic weights of all 12 traits, except fruit size variation (VFSZ) and plant size, were positive (Table 1). The aggregate economic genotype value for the 3008 genotypes in the breeding program pedigree file ranged from -0.36 to +0.28 when zero was set as 'Festival' (Table 2). The maximum EBV for a trait (i.e., the sum of the overall mean and the estimated breeding value as the deviation from mean) varied with trait but was from one and a half to three times as high as the minimum breeding value (Table 1). Examples of EBVs for 20 cultivars within the pedigree file can be calculated by dividing values in Table 3 by corresponding economic weights of Table 1 . The correlation between the $\mathrm{H}$ of 13 (past and current) commercial cultivars and the year (1945-98) of the cultivar's selection (Table 3 ) was significant $(P<0.001)$ and linear $\left(R^{2}=0.77\right)$. Recent releases had high $\mathrm{H}$ values (Table 3 ).

RELATIONSHIP BETWEEN AGGREGATE ECONOMIC GENOTYPE AND GROSS MARGIN. The gross margins were highly correlated $\left(R^{2}=0.89\right.$ to 0.99 ) with $\mathrm{H}$ values (Fig. 1). Presently, the industry grows $\approx 35$ million plants on an area of 780 ha. When the area planted to a particular genotype was less than $50 \%$ of available area, the GMs for the genotypes were linearly related $\left(R^{2}=0.99\right)$ to the $\mathrm{H}$ values of the genotypes (Fig. 1). As the
Table 1. Estimated economic weights for 12 selection traits in strawberry improvement.

\begin{tabular}{lccc}
\hline Trait code & $\begin{array}{c}\text { Base } \\
\text { value }^{\mathrm{y}}\end{array}$ & $\begin{array}{c}\text { Economic } \\
\text { wt }(v) \text { for trait }\end{array}$ & $\begin{array}{c}\text { Range of EBV for } \\
\text { 3008 genotypes } \\
\text { from pedigree }\end{array}$ \\
\hline TYLD & 702.5 & 0.000165 & $295-1037$ \\
EYLD & 216.5 & 0.001242 & $112-299$ \\
FRSZ & 17.44 & 0.021395 & $9.4-25.4$ \\
VFSZ & 3.373 & -0.00141 & $2.1-4.2$ \\
RRDP & 71.9 & 0.000306 & $39.0-83.0$ \\
REBR & 5.95 & 0.005455 & $3.3-6.9$ \\
REAB & 7.15 & 0.002462 & $4.9-7.9$ \\
APSH & 5.57 & 0.01069 & $3.9-6.7$ \\
DSPR & 5.92 & 0.003798 & $4.9-6.7$ \\
TRST & 7.11 & 0.001723 & $4.4-8.1$ \\
PLZR & 4.58 & -0.00514 & $2.9-6.0$ \\
EDPK & 6.63 & 0.004144 & $5.6-7.3$ \\
\hline
\end{tabular}

${ }^{\mathrm{z}}$ 1) Measured traits: TYLD = total yield (g/plant) May through August; EYLD = early yield (g/plant) May through June; FRSZ = fruit size (g/ fruit), derived from season's total weight and number; VFSZ = variation in fruit size ( $\mathrm{g} /$ fruit) as SE of fruit size across weekly harvests; $\mathrm{RRDP}_{\mathrm{P}}=$ resistance to rain damage as percentage (by number) of fruit not damaged following rain; 2) rated traits (1 to 9 rating scale with increasing intensity of trait): REBR $=$ resistance of fruit to bruising; $\mathrm{REAB}=$ resistance of fruit surface to abrasion; $\mathrm{APSH}=$ fruit appearance (shape) rating is a visual assessment of regularity and uniformity of fruit shape; DSPR = display of fruit (i.e., position of fruit relative to foliage); TRST = truss type (i.e., rating based on the proportion of primary, compared with secondary, tertiary, etc., fruit based on branching within inflorescence); PLZR = plant size rating; $\mathrm{EDPK}=$ ease of detaching (picking) fruit from pedicel.

'Base values are for 'Festival' as an estimated breeding value (i.e., breeding value deviations from mean plus overall mean) extracted from the ASReml output tables after mixed model analysis of data combined across years 2004 through 2009 with pedigree and spatial effects included (Gilmour et al., 2006). ASReml is a statistical package that fits linear mixed models using residual maximum likelihood (REML).

${ }^{\mathrm{x}}$ Change in profitability index/unit change in trait (i.e., $\triangle \mathrm{PI} / \triangle$ unit) where profitability index is the ratio of gross margin to input costs. ${ }^{\mathrm{w}} \mathrm{EBV}=$ estimated breeding value (i.e., breeding value deviations from mean plus overall mean).

percentage of the planting allocated to the particular genotype increased above $50 \%$, the relationship became non-linear and was better described by a quadratic relationship $\left(R^{2}=0.96\right.$ to $0.99)$ or an asymptotic relationship $\left(R^{2}=0.95\right.$ to 0.99$)$ (Fig. 1), although linear regression still explained a high proportion of the variation $\left(R^{2}=0.89\right)$ at $100 \%$ of planting (Fig. 1$)$. The quadratic relationship implies a maximum that will be followed by a decrease, whereas an asymptotic relationship implies approaching a maximum with each marginal increase being smaller (i.e., approaching a limit) but no definite maximum. Additionally, when a higher percentage of a planting was occupied by a genotype, the variance of the GM was higher at higher $\mathrm{H}$ values such that at $100 \%$ of planting (Fig. 1), the upper (positive) half of distribution the $H$ values of 15 genotypes was not well related to $\operatorname{GM}\left(P=0.23, R^{2}=0.04\right)$.

EFFECT OF ELIMINATING INDIVIDUAL TRAITS ON THE AGGREGATE ECONOMIC GENOTYPE VALUE. Excluding one of a pair of traits that are highly correlated $(r>0.7)$, e.g., total yield with early yield, and resistance to abrasion with resistance to bruising had no significant effect on the ranking of genotypes. 
Table 2. Ranges of values of individual components of the aggregate economic genotype $(\mathrm{H})^{\mathrm{z}}$ - the linear combination of estimated breeding value $(a)$ of genotype $\times$ economic weight $(v)$ for each trait for 3008 strawberry genotypes - and percentage trait contribution to range of $\mathrm{H}$.

\begin{tabular}{|c|c|c|c|c|}
\hline Trait $^{y}$ & Maximum $v a^{\mathrm{x}}$ & Minimum $v a^{\mathrm{x}}$ & Maximum $v a-$ minimum $v a^{\mathrm{x}}$ & Contribution to $\mathrm{H}(\%)^{\mathrm{w}}$ \\
\hline $\begin{array}{l}\text { TYLD } \\
\end{array}$ & 0.05538 & -0.07075 & 0.12613 & 20 \\
\hline FRSZ & 0.17178 & -0.17184 & 0.34362 & 54 \\
\hline $\operatorname{RRDP}_{\mathrm{P}}$ & 0.00035 & -0.00100 & 0.00135 & 0 \\
\hline REBR & 0.00507 & -0.01437 & 0.01944 & 3 \\
\hline REAB & 0.00176 & -0.00549 & 0.00725 & 1 \\
\hline TRST & 0.00165 & -0.00459 & 0.00624 & 1 \\
\hline PLZR & 0.00880 & -0.00739 & 0.01619 & 3 \\
\hline EDPK & 0.00295 & -0.00415 & 0.00710 & 1 \\
\hline $\mathrm{H}^{\mathrm{v}}$ & 0.28208 & -0.35645 & 0.63852 & 100 \\
\hline
\end{tabular}

${ }^{\mathrm{z}} \mathrm{H}$ is the linear combination, summed across 12 traits, of $a$ for each trait $\times v$ of each trait and all 3008 genotypes for which breeding values were estimated.

${ }^{y}$ 1) Measured traits: TYLD = total yield (g/plant) May through August; EYLD = early yield (g/plant) May through June; FRSZ = fruit size (g/ fruit), derived from season's total weight and number; VFSZ = variation in fruit size ( $\mathrm{g} /$ fruit) as SE of fruit size across weekly harvests; $\mathrm{RRDP}_{\mathrm{P}}=$ resistance to rain damage as percentage (by number) of fruit not damaged after rain; 2 ) Rated traits (1 to 9 rating scale with increasing intensity of trait): $\mathrm{REBR}=$ resistance of fruit to bruising; $\mathrm{REAB}=$ resistance of fruit surface to abrasion; APSH $=$ fruit appearance (shape) rating is a visual assessment of regularity and uniformity of fruit shape; DSPR = display of fruit (i.e., position of fruit relative to foliage); TRST = truss type (i.e., rating based on the proportion of primary, compared with secondary, tertiary, etc., fruit based on branching within inflorescence); PLZR = plant size rating; EDPK = ease of detaching (picking) fruit from pedicel.

${ }^{\mathrm{x}}$ Maximum $v a$ and minimum $v a$ are for each trait the highest and lowest individual values, respectively, estimated for the linear combination of $a$ of genotype $\times v$ of component trait and maximum $v a$ - minimum $v a$ gives the range of values for each trait.

${ }^{\mathrm{w}}$ Contribution to $\mathrm{H}$ for a trait is the range of values for the trait compared with the range of values of aggregate economic genotype; i.e., $\{[$ (maximum $v a-$ minimum $v a$, of component trait $) /($ maximum $\mathrm{H}-$ minimum $\mathrm{H}$, i.e., 0.63852$)] \times 100\}$. The sum of trait percentages does not necessarily add to 100 , because individual trait ranges are independent.

${ }^{v}$ Values of $\mathrm{H}$ including maximum, minimum, and range.

Similarly, excluding the trait variation in fruit size, a trait that was considered to be of only minor importance because the range of $v a$ for this trait was less than $1 \%$ of the range of $\mathrm{H}$, had no significant effect on the ranking of genotypes. In each case, the Spearman's rank correlation value was greater than or equal to 0.98 for all sets of genotypes tested (Table 4).

\section{Discussion}

VALIDATION THAT AN AGGREGATE ECONOMIC GENOTYPE IS AN APPROPRIATE ESTIMATE OF CURRENT ECONOMIC WORTH. Once economic weights of traits are developed and the breeding value of genotypes for traits estimated and combined into an aggregate economic genotype, it is necessary to validate the estimate of $\mathrm{H}$ in a current commercial context. The high linear correlation $\left(R^{2}=0.77\right)$ between the year $(1945-98)$ when the cultivar was selected and the $\mathrm{H}$ value of 13 commercially significant cultivars (Table 3) implies that $\mathrm{H}$ reflects the economic worth of a genotype within the current production and marketing system. In a competitive market, the adoption of an innovative (and profitable) technology (e.g., a more profitable cultivar) increases and marginal profit decreases until a normal profit equilibrium is reached (Carbaugh, 2010). By this stage of adoption, the deployment of a superior cultivar (or other a technological advance) is necessary to renew the higher profit cycle. Thus, the relationship between time of introduction and $\mathrm{H}$ is to be expected and implies that $\mathrm{H}$ should validly reflect the present economic worth of the genotype. However, some care is presently required in relying on this relationship in the present study because it is based on a limited sample size (i.e.,
13 data points). Breeding programs aim to release new cultivars to increase profitability for the producer; thus, the selected cultivars should increase the GM, which is an indicator of profitability.

RELATIONSHIP BETWEEN AGGREGATE ECONOMIC GENOTYPE AND GROSS MARGIN. Strong correlations would be expected between the aggregate economic genotype and the GM for a genotype because changes in GM were used to develop the economic weights for traits and such associations are evident (Fig. 1). However, there are two responses that were initially unexpected.

First, the relationship between GM and $\mathrm{H}$ becomes increasingly non-linear as the percentage of planting dedicated to the genotype increases above $50 \%$. In practice, as producers increase production by trying to take advantage of a technological innovation to increase profitability, the increased supplies, particularly for non-exportable goods, tend to drive down prices (until the remaining producers again achieve normal profits for their industry). Consequently, in these situations, the GM relationship with production often starts as linear and then asymptotes as a result of diminishing marginal returns (Malcolm et al., 2005). Producers throughout the industry usually plant two or three cultivars at varying proportions in any single season (see Herrington et al., 2012). This occurs both to even out production peaks and as a consequence of gradual genetic replacement process as new profitable genotypes enter and other less profitable genotypes withdraw from the production environment. These industry features reduce the likelihood of one cultivar dominating production in the region.

Second, when a genotype occupies a high percentage of the industry planting, the variation in GM is greater when $\mathrm{H}$ is 


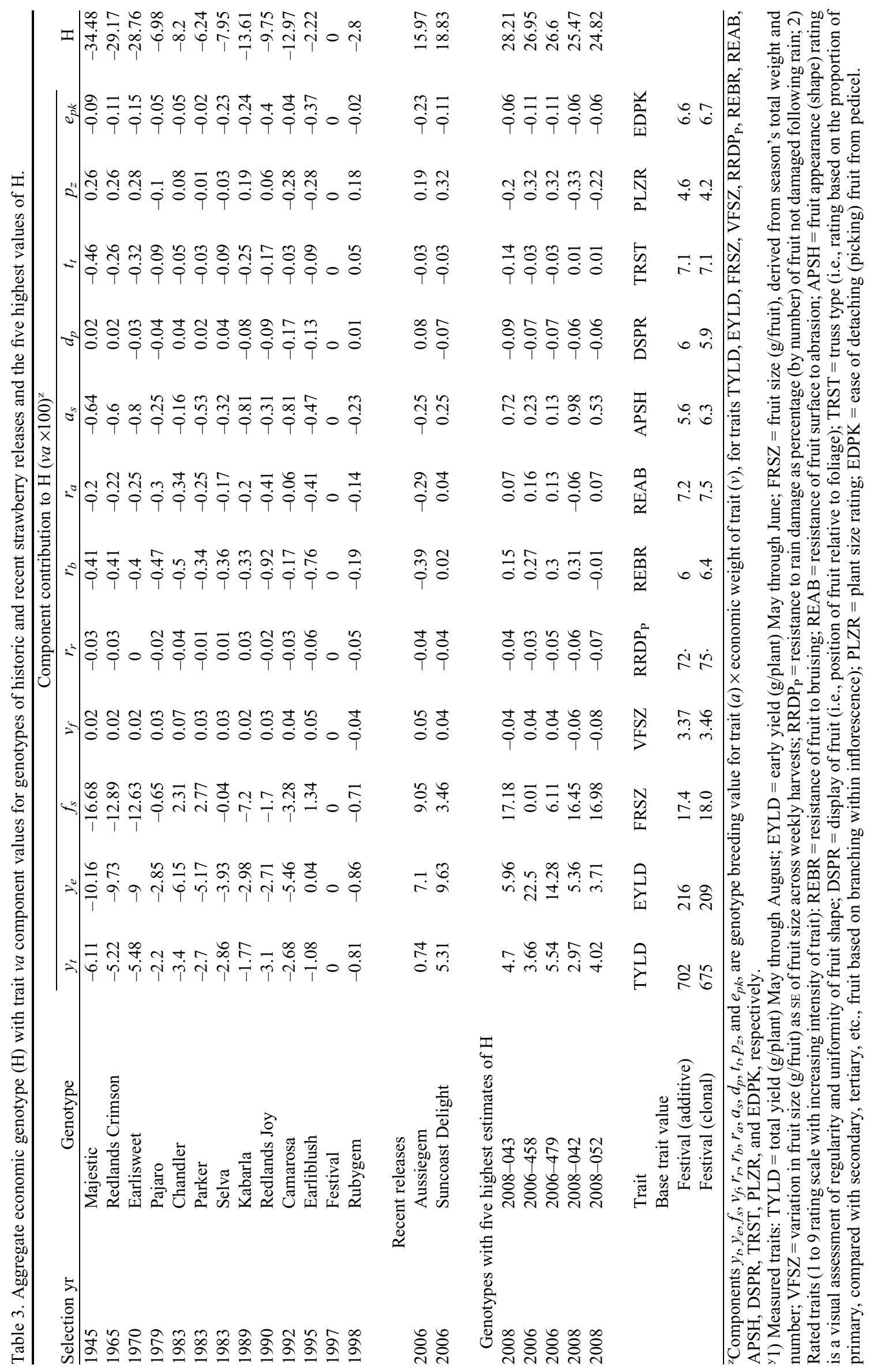




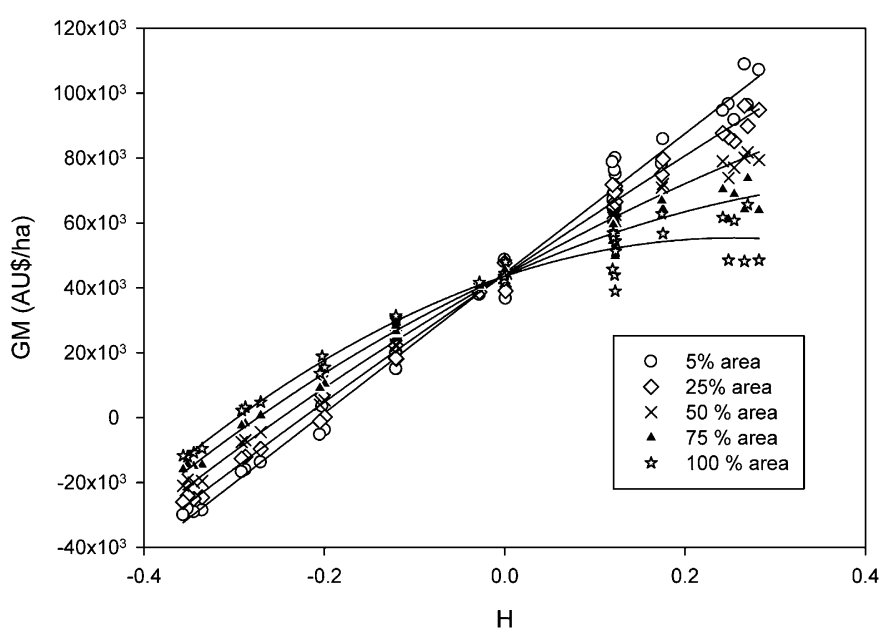

Fig. 1. Relationship between estimated gross margin $\left(\mathrm{GM}_{\mathrm{N} \%}\right)$ and aggregate economic genotype $(\mathrm{H})$ of 32 genotypes when a genotype is planted on $5 \%$, $25 \%, 50 \%, 75 \%$, and $100 \%$ of available planting area. $\mathrm{GM}_{5 \%}=44,444( \pm 800)+$ $\mathrm{H} \times 215,394( \pm 3,740)\left(R^{2}=0.991\right) ; \mathrm{GM}_{25 \%}=42,591( \pm 565)+\mathrm{H} \times 192,297( \pm$ $2,640)\left(R^{2}=0.994\right) ; \mathrm{GM}_{50 \%}=40,275( \pm 621)+\mathrm{H} \times 163,426( \pm 2,906)\left(R^{2}=\right.$ $0.990) ; \mathrm{GM}_{75 \%}=43,665( \pm 914)+\mathrm{H} \times 124,561( \pm 2,926)+\mathrm{H}^{2} \times-128,305( \pm$ $16,132)\left(R^{2}=0.989\right) ; \mathrm{GM}_{100 \%}=43,558( \pm 1,483)+\mathrm{H} \times 92,885( \pm 4,750)+\mathrm{H}^{2} \times$ $-182,491( \pm 26,184)\left(R^{2}=0.956\right)$ : Here all coefficients $( \pm \mathrm{SE})$ and all regressions are highly significant at $P<0.001$. The base gross margin for a field planted $100 \%$ to 'Festival' is AU $\$ 44,429 /$ ha and for a field planted $50 \%$ 'Festival' $: 50 \%$ 'Rubygem' is AU \$44,989/ha.

Table 4. Spearman's rank correlations between $\mathrm{H}_{0}$ (aggregate economic genotype with all traits included in estimating $\mathrm{H}$ ) and $\mathrm{HT}_{\mathrm{n}}$ (aggregate economic genotype with trait ${ }_{\mathrm{n}}$ excluded when estimating $\mathrm{H}$ ) with different numbers and sets of strawberry genotypes.

\begin{tabular}{lccc}
\hline \multirow{2}{*}{ Trait $^{\mathrm{z}}$} & \multicolumn{3}{c}{ Genotypes (no.) } \\
\cline { 2 - 4 } REAB (REBR, $\left.r_{\mathrm{A}}=0.82\right)$ & $1.008^{\mathrm{y}}$ & $247^{\mathrm{x}}$ & $32^{\mathrm{w}}$ \\
TYLD (EYLD, $\left.r_{\mathrm{A}}=0.75\right)$ & 0.99 & 1.00 & 0.99 \\
VFSZ (contributes less than 1\% to H) & 1.00 & 1.00 & 0.99 \\
\end{tabular}

${ }^{\mathrm{z}}$ Correlated traits $\left(\mathrm{r}_{\mathrm{A}}=\right.$ correlation coefficient of raw additive values): TYLD = total yield, EYLD = early yield, REBR = resistance of fruit to bruising, REAB = resistance of fruit surface to abrasion. Low contributing trait: VFSZ = variation in fruit size likely contributes little to $\mathrm{H}$ (see Table 1).

${ }^{\mathrm{y}}$ Full pedigree of 3008 genotypes, approximately half the genotypes had $\mathrm{H}$ values based only on predicted estimated breeding values; i.e., they were in ancestral pedigrees but had not been directly evaluated in any field trials.

${ }^{\mathrm{x}}$ Subset of 247 genotypes were a sample that had data from at least one season 2004-09.

wSubset of 32 genotypes were a sample that had data from at least one season 2004-09 but were also sampled to cover the whole range of $\mathrm{H}$ values in pedigree.

positive than when $\mathrm{H}$ is negative. This is perhaps expected, because at a higher proportion of planting, the expression of the traits of a genotype would more likely be sufficient to influence the market (e.g., higher yield leading to lower prices) and certainly the consequences of expression would become more apparent. Although $\mathrm{H}$ assumes a linear relationship with value and level of each trait, the GM profit function may be non-linear with level of a trait, e.g., reduced prices may result because of increased mass of fruit on the market (see price function of
Herrington et al., 2012). In fact, three of six genotypes with among the highest values of $\mathrm{H}$ (i.e., 0.25 to 0.28 ) had a GM of approximately AU \$50,000/ha (see lower right data points on Fig. 1), but these were also the genotypes with the highest total yields (30\% to $50 \%$ higher than those of 'Festival'). This implies that on the basis of $\mathrm{H}$ alone, these would have been selected, whereas on the basis of GM alone, they were less than optimal and would likely not have been selected.

Using the aggregate economic genotype is efficient for selection; however, relying on $\mathrm{H}$ alone may result in substantial productivity (grams per plant and tonnes per hectare) increases, but with limited industry-wide financial benefit. Financial risks would also increase because the GM may be produced from a higher cost base [e.g., 'Festival' as the sole cultivar has an approximate gross margin of AU $\$ 44,429 /$ ha, which is built on costs of $\mathrm{AU} \$ 179,617 / \mathrm{ha}$; by contrast, one of these highest yielding genotypes has a gross margin of AU \$48,191/ha, but it is built on costs of AU $\$ 211,177 /$ ha. Thus, for approximately AU $\$ 4000 /$ ha $(10 \%)$ increase in GM, costs increased by $\mathrm{AU}$ $\$ 31,560 /$ ha $(18 \%)]$. The aggregate economic genotype is efficient in identifying economically superior genotypes, but investigation of the consequences of deployment to a varying proportion of total industry plantings on the GM would be a useful, and perhaps even an essential, adjunct if the main aim for the breeding is increasing producer profitability. Although such investigations are beyond the scope of the present study, they may lead to altered strategies for commercial deployment of new cultivars across the whole of industry (e.g., a programmed build-up of commercial plant numbers in line with consumer fruit demand or nominating specified production windows for new genotypes).

EFFECT OF ELIMINATING INDIVIDUAL TRAITS ON THE AGGREGATE ECONOMIC GENOTYPE VALUE. Reducing development costs by using fewer trait evaluations would be beneficial to breeding programs. This can be done if alternative evaluation processes give similar rankings of genotypes. The high rank correlation coefficients between an aggregate economic genotype estimated with and without including one of three traits (Table 4) implies that, in the breeding population, the data required to estimate the relative merit of a genotype can be reduced. Omission of total yield, resistance to abrasion, or variation in fruit size from the function for $\mathrm{H}$ is optional, although the effect of omitting two or more traits simultaneously has not yet been evaluated.

In the analysis, the total planting area was considered stable, and this was true for 2005 through 2010 (Herrington et al., 2012). Individual farms have increased in area over this period, because fewer farms continued operating. Any future increase in production area may affect the GM and relationship with $\mathrm{H}$. This hypothesis requires further data collection and analysis on plant numbers for individual cultivars, yield and fruit size, area of production, market prices, and market destinations.

According to Ponzoni and Newman (1989), the ideal breeding objective (i.e., the ideal aggregate economic genotype) should comprise all traits that influence returns and costs, regardless of whether they can be changed by selection or measured. Consumer quality attributes would be important traits influencing returns and therefore should be included in estimating H. To minimize complexity in the present study, the consumer quality attributes were assumed to be constant (i.e., stable across environments), sufficiently high so as not to adversely affect demand and equal among genotypes, and could therefore 
be excluded from the linear model estimating the aggregate economic genotype. In reality, there is likely to be genetic variation for traits affecting consumer perception of quality, and so further work is desirable to incorporate these traits into the estimate of $\mathrm{H}$. This work should focus on estimating the relative contribution of consumer quality traits to total price. Estimates of breeding values of many consumer traits in the population are available (M.E. Herrington, unpublished data), but economic weights are not yet available. Fortunately, once these weight estimates are available, they could be readily included into a new model of the aggregate economic genotype.

New cultivars will usually be planted on a small proportion of a farm's production area in the early phase of commercial adoption. Rapid adopters may plant a large proportion of the individual farm, but the combined area occupies only a small percentage of overall industry area. For genotypes with high $\mathrm{H}$, such early adoption offers substantial benefits in profitability (high gross margin in Fig. 1) to the producer(s) using the genotype. This encourages further adoption. However, increasing the proportion planted to a genotype differentially affects the gross margin of the genotype. For example, the GM at the highest value of $\mathrm{H}$ is approximately $\mathrm{AU} \$ 95,000 /$ ha at $25 \%$ of planting (Fig. 1), whereas the gross margin is only AU $\$ 40,000$ / ha when all of industry plants only that genotype (i.e., $100 \%$ of planting; Fig. 1). This indicates a financial step backward because the latter GM is less than the original base line gross margin (approximately AU \$44,429/ha). One might expect that a suite of genotypes would have an optimal proportional distribution of planting, which maximizes the GM.

This study has provided the first estimates of values of the aggregate economic genotype or breeding objective for subtropical strawberry by combining the economic weights and genetic breeding values for 12 traits. The estimates are consistent with the historical use of cultivars in southeast Queensland and will be useful in choosing among selections for clonal deployment and parents for crossing. However, for those genotypes with a high $\mathrm{H}$ and being considered for commercial deployment, additional evaluation using the GM is also warranted to ensure economic gain for industry.

\section{Literature Cited}

Apiolaza, L.A. and D.J. Garrick. 2001. Breeding objectives for three silvicultural regimes of radiata pine. Can. J. For. Res. 31:654-662.

Barwick, S.A., W. Fuchs, and R. Fenwick. 1991. Breeding objectives and selection indices for use with Breedplan: B-Object. Handbook International Breedplan School. Animal Genet. Breeding Unit, Univ. New England, Armidale, New South Wales, Australia.

Barwick, S.A. and A.L. Henzell. 2005. Development successes and issues for the future in deriving and applying selection indexes for beef breeding. Aust. J. Exp. Agr. 45:923-933.

Barwick, S.A., D.J. Johnston, H.U. Graser, G.R. Griffith, and R.J. Farquharson. 2003. Assessment of genetic trends and aggregation of benefits from genetic improvement over industry breed $\mathrm{x}$ market production systems. New South Wales Agriculture, Orange, New South Wales, Australia.

Bauer, A.M. and J. Leon. 2008. Multiple-trait breeding values for parental selection in self-pollinating crops. Theor. Appl. Genet. 116:235-242.

Brascamp, E.W., C. Smith, and D.R. Guy. 1985. Derivation of economic weights from profit equations. Anim. Prod. 40:175-180.

Carbaugh, R.J. 2010. Contemporary economics: An applications approach. 6th Ed. M.E. Sharpe, Armonk, NY.

Dieters, M.J., G.R. Hodge, and T.L. White. 1996. Genetic parameter estimates for resistance to rust (Cronartium quercuum) infection from full-sib tests of slash pine (Pinus elliottii), modelled as functions of rust incidence. Silvae Genet. 45:235-242.

Dieters, M.J., T.L. White, R.C. Littell, and G.R. Hodge. 1995. Application of approximate variances of variance-components and their ratios in genetic tests. Theor. Appl. Genet. 91:15-24.

Doupe, R.G. and A.J. Lymbery. 2003. Toward the genetic improvement of feed conversion efficiency in fish. J. World Aquacult. Soc. 34:245-254.

Durel, C.E., F. Laurens, A. Fouillet, and Y. Lespinasse. 1998. Utilization of pedigree information to estimate genetic parameters from large unbalanced data sets in apple. Theor. Appl. Genet. 96:1077-1085.

Falconer, D.S. and T.F.C. Mackay. 1996. Introduction to quantitative genetics. Longman, Harlow, UK.

Gilmour, A., B. Gogel, B. Cullis, and R. Thompson. 2006. ASReml user guide. Release 2.0. VSN International, Hemel Hempstead, UK.

Hardner, C.M., I.S.E. Bally, and C.L. Wright. 2012. Prediction of breeding values for average fruit weight in mango using a multivariate individual mixed model. Euphytica 186:463-477.

Hardner, C.M., B.L. Greaves, C. Coverdale, and M. Wegener. 2006. Applications of economic modelling to support selection decisions in macadamia, p. 431-436. In: Mercer, C.F. (ed.). Proc. 13th Australasian Plant Breeding Conf., 18-21 Apr. 2006, Christchurch, New Zealand. Hazel, L.N. 1943. The genetic basis for constructing selection indexes. Genetics 28:476-490.

Henderson, C.R. 1975. Best linear unbiased estimation and prediction under a selection model. Biometrics 31:423-447.

Herrington, M., M. Wegener, C. Hardner, L. Woolcock, and M. Dieters. 2012. Influence of plant traits on production costs and profitability of strawberry in southeast Queensland. Agr. Syst. 106:23-32.

Lynch, M. and B. Walsh. 1998. Genetics and analysis of quantitative traits. Sinauer Assoc., Sunderland, MA.

Malcolm, L., J. Makeham, and V. Wright. 2005. The farming game: Agricultural management and marketing. Cambridge Univ. Press, New York, NY.

Melton, B.E. and W.A. Colette. 1993. Potential shortcomings of output input ratios as indicators of economic-efficiency in commercial beef breed evaluations. J. Anim. Sci. 71:579-586.

Mrode, R.A. 2005. Linear models for the prediction of animal breeding values. CABI Publ., Wallingford, UK.

Oakey, H., A. Verbyla, W. Pitchford, B. Cullis, and H. Kuchel. 2006. Joint modeling of additive and non-additive genetic line effects in single field trials. Theor. Appl. Genet. 113:809-819.

Ponzoni, R.W. 1988. The derivation of economic values combining income and expense in different ways: An example with Australian Merino sheep. J. Anim. Breed. Genet. 105:143-153.

Ponzoni, R.W. and S. Newman. 1989. Developing breeding objectives for Australian beef cattle production. Anim. Prod. 49:35-47.

Queensland Strawberry Industry Promotions Council. 2006. Queensland strawberry industry average gross margin-As of Oct. 2006. 30 May 2011. <http://www.qldstrawberries.com.au/data/gross_ margin_2006_calcs.htm>.

Silva, J.C.E., N.M.G. Borralho, and B.M. Potts. 2004. Additive and non-additive genetic parameters from clonally replicated and seedling progenies of Eucalyptus globulus. Theor. Appl. Genet. 108:1113-1119.

Smith, C., J.W. James, and E.W. Brascamp. 1986. On the derivation of economic weights in livestock improvement. Anim. Prod. 43:545-551.

Solkner, J., H. Grausgruber, A.M. Okeyo, P. Ruckenbauer, and M. Wurzinger. 2008. Breeding objectives and the relative importance of traits in plant and animal breeding: A comparative review. Euphytica 161:273-282.

Souza, V.A.B.D., D.H. Byrne, and J.F. Taylor. 2000. Predicted breeding values for nine plant and fruit characteristics of 28 peach genotypes. J. Amer. Soc. Hort. Sci. 125:460-465.

Tancred, S.J., A.G. Zeppa, M. Cooper, and J.K. Stringer. 1995. Heritability and patterns of inheritance of the ripening date of apples. HortScience 30:325-328.

Wenzel, W.G. 1980. Correlation and selection indices in strawberry breeding. Agroplantae 12:29-32. 